\title{
Computer-aided Access to Tactile Graphics for the Blind
}

\author{
Jürgen Lötzsch \\ InNOVATIVE TECHNIKEN des BSVS e.V. \\ Weissbachstrasse 5, D-01069 Dresden, Germany
}

\begin{abstract}
Every day sighted people use 2D graphic representations of informations for communication and documentation. At school and work but also in the daily life they bring a lot of advantages especially efficiency and speed. Now we see all of them on computer screens. But how can blind people manage the access to such $2 \mathrm{D}$ representations used in computers ? The experiences, gained during the author's involvement in projects dealing with audio-tactile pictures, are presented in this paper.
\end{abstract}

\section{2D Representations of Informations}

Every day sighted people use 2D graphic representations of informations for communication and documentation. 2D representations bring very many advantages. They are needed to achieve the aims of efficiency and speed.

You can find numerous types of graphic representations, particulary at school, at work and during the studies. Beside the various graphics from basic disciplines as for example mathematics, physics, chemistry, biology, geography, astronomy and anatomy they are also used for building civil engineering drawings, arrow diagrams, structured programs, flow charts, circuit diagrams, piping network diagrams for drinking and heating water among others.

Beside these types of 2D representations related to education and job you can also find a lot of interesting pictures, graphics and diagrams in the daily life as e.g. city maps (historical, modern and referring to development); network plans of buses, trams and so on; maps for different purposes (tourists, weather, economy, ...); surveys of museums, exhibitions, parks and gardens; ground plans and elevations of historical buildings (churches, theaters, castles, fortresses, etc.), representations of the functional structure of administration and service institutions (townhalls, banks, insurance companies etc.); surveys of the situation of departments in shopping centers, supermarkets; schematic representations of railway stations with their 
platforms, counters and service; surveys of medical institutions (hospitals, health centers); schematic representations of sports facilities, grounds for ball games etc.

Whereas in former times these 2D representations usually were available only on sheets of paper now we see all of them on computer screens. Furthermore computer science itself created a lot of new ones e.g. graphic user interfaces for operating systems and application programs.

But how can blind people manage the access to $2 D$ representations used in computers?

Following VANDERHEDEN [13] there are three tasks of different types:

a) Graphical user interfaces (GUI) on the computers (operating systems)

b) Graphical user interfaces on public information systems

c) Access to graphics.

The theme of the paper is "Acces to graphics" where "graphics" is used in the sense of the examples above without any consideration of GUI.

\section{From Graphics to Tactile Graphics for Blind People}

Blind people are able to compensate seeing by feeling and listening. Therefore it is necessary to "translate" the given 2D graphic representations of informations into tactile and/or audible ones.

Of course it would be very pleasant if one could get the tactile and/or audible graphic for the blind in a 1-to-1 manner from the original graphic. But usually this "translation" process is very complicated and the portion of manual work is considerably which has to follow certain design rules (see e.g. [5]). Only in some cases you can write a translator which automatically transforms a certain class of graphics for sighted people into graphics for the blind. This has been done for instance for special business charts [6].

But usually it is impossible to do so because of the complexity of the picture. An impressive example for such a graphic is a city map.

But problems arise already when considering texts. "Scientific literature is usually presented to sighted readers in a multi-dimensional format. It is multi-dimensional in the sense that the information is contained not just in the words themselves, but also in the positions of the words and in the fonts used in printing the words." [1]

Examples for that are two-dimensional mathematical notations, chemical formulas, and so on. Sighted people use this kind of representations because they possess the advantage of a clear arrangement of the semantic structure of the formula. Why transforming it into a linear braille form when its clarity is lost by doing this? This 
is the basic idea of DotsPlus and ASTER developed by BARRY, GARDNER and RAMAN for scientific documents [1].

In such 2D formulas only a few very simple graphic elements arise such as horizontal lines, symbols for sum, integration and so on, which have a very close relationship to the alphabets of formal grammars [7]. It seems to be an interesting approach to apply translator writing techniques to the problem of transforming general pictures into audible and tactile ones.

But the bigger the portion of graphic elements is in the picture the greater are the problems to be solved when preparing the picture for the blind.

Therefore in many cases it is a long way from the prototype of a graphic to its equivalents for blind people. And although this process can be supported by the computer it remains a lot of manual work for which you have to have the right feel. Not too much objects in the graphic means e.g. you have to concentrate on the essential content, you have to leave out the unnecessary details, you have to split the graphic into several ones, you have to enlarge it, and so on.

One big problem is text on graphics. Why?

The first reason is that braille text is also a tactile object. All textual objects must be touched in addition to the objects of the pure underlying graphic. They increase the complexity of the picture and decrease the threshold of its recognizability. Furtheron must be taken in consideration that only $15-25 \%$ of the blind people are able to read braille.

One piece of text gives an explanation to a certain object of the graphic. As the braille text must have a minimum size it is very often difficult to place it in the right position to the corresponding object. In such cases you can

- replace the full text by a braille label and integrate all labels into an appendix with the full texts,

- or you can place the text in the surrounding of the picture and draw an arrow to the belonging to object (but this arrow is an additional tactile object again that must be recognized including at which graphic object the arrowhead is pointing)

- or you can remove the texts completely from the picture and write a guide through the picture which can be printed in braille or be recorded on tape

- or you can leave out the text assuming that a partner will explain the graphic objects to you when you are asking him.

Therefore we can distinguish between the following types of tactile graphics

1. Full text graphics possibly with pointers

2. Labelled graphics (with additional legend) possibly with pointers

3. Textual guided pure graphics (with an additional guide in braille or on tape)

4. Pure graphics (requires help by a human being or by a computer) . 
Undoubtedly the pure graphics posses an extraordinary importance when they are combined with a computer as dialogue "partner".

A pure graphic contains only the graphic objects and no additional braille or additional arrows to be touched. Therefore in one graphic you can place more graphic objects until the threshold of recognizability is exceeded.

Pure graphics which can be explained by the computer are called audio-tactile graphics.

From the computer partner is expected that it will guarantee the independent navigation through the graphic by the blind.

\section{Audio-Tactile Dialogue Systems}

An audio-tactile dialogue system offers blind people as the user of the system the access to tactile graphics:

- A blind person explores a tactile graphics in the usual manner using its fingers.

- If he/she wishes to get informations about a certain object in the graphic he/she requests them.

- He/she listens to the informations given on the audio channel.

Unfortunately until now it was not possible to find a safe and cheap solution of a graphic display for the blind, where the contents of the screen is displayed in tactile form. First steps in the right direction have been done by Schweikhart, Fricke/Bähring, Shinohara et al., Schulz and others.

Therefore at present only one solution seems to be reasonable: the efficient design and production of tactile graphics on paper or foil and the preparation of them for the dialog between the blind users and the computer.

The general scheme of an audio-tactile dialogue system is the following:

1. There must be a place where the tactile graphic can be touched.

2. When putting the graphic there it must be identified by the system.

3. It must be possible to feel the graphic in the usual manner and furtheron to point to a chosen graphical object.

4. The system must be able to identify the pointing position and the chosen object.

5. The system has to react by generating an information and sending it through the audio channel.

Hardware. You can access the objects of a graphic when you place it on a digitizing tablet or a touch window which are commercially available. 
The audio information can be generated using a sound card. Text can be handled in two different ways: sending digitized speech to the sound card or alphanumerical text to a text-to-speech synthesizer. The synthesizer itself is either software working on a sound card or an electronic device.

Especially for use in a audio-tactile system PARKES developed his Nomad board about in $1988[10,11]$. It is a touch board combined with an integrated speech synthesizer. Since 1991 it is produced by Quantum Technology Pty. Ltd. Rydalmere, Australia. The American Printing House for the Blind (APH) took a licence and since March 1993 they make Nomad too [4].

Software systems. Some attempts have been made to design and implement audiotactile dialogue systems.

The first one was PARKES's Nomad system especially working with the Nomad board connected to a MS-DOS computer with the Nomad software.

The Dresden AUDIO-TOUCH system Version 1.0 was ready in 1992 [8]. It can be configured for different digitizers and Touch Windows and for different text-tospeech synthesizers as well as for SoundBlaster cards with software synthesizers. It is working also on the Nomad board. The authors prefer to use a sound card with talking blaster because of the the speech quality and the integration of sound.

BLENKHORN reported in March 1994 the principal features of the Talking Tactile Maps System [2]. The hardware used is an IBM compatible computer with a Touch Window and a text to speech synthesizer. Evaluations have been undertaken to date in a school.

VANDERHEIDEN illustrated in [13] a technique for accessing the picture on the computer screen. You need a tactile copy of the screen picture, put it on a Touch Window and explore it supported by a screen reader.

\section{Audio-Touch}

Visually impaired persons use the AUDIO-TOUCH system with the traditionally media for tactile information. Such media exist in different types such as

- relief of foil

- swelling paper with mechanically produced graphics

- paper embossed with a braille printer

- foil embossed with an embossing plotter

- textile materials embroidered with a sewing machine etc.

AUDIO-TOUCH can be operated with different materials.

Graphics for AUDIO-TOUCH are designed using standard software such as Designer, CorelDraw and others. The implementation for AUDIO-TOUCH is then 
done automatically. Furtheron there is an integrated component for scetching audiotactile graphics.

Each graphic consists of a set of graphic objects. The simplest form of a dialogue is to point to an object and to listen to the objects name spoken by the speech synthesizer. Demanding discourses can be designed on further talking levels. On each talking level sequences of text and sound can be assigned to the graphic objects. Each talking level represents certain semantics of the underlying graphic.

Series of graphics have been prepared for AUDIO-TOUCH from different fields of application: dialogue on mathematical functions and planar geometry, information about touristics and sightseeing, maps in geography, mobility training using tactile maps of railway stations and traffic networks, course on Windows graphical user interfaces, anatomy course for blind masseurs.

\section{Conclusions}

The application of systems like AUDIO-TOUCH in the area of education or in the tourism field or as an information system for exhibitions is "both enjoyable and useful" [2]. There is no doubt that audio-tactile dialogue system have a wide application field. They will improve the access to 2D representations of informations by blind people considerably.

\section{References}

1. Barry, Gardner, Raman: Accessibility to Scientific Information by the Blind: DotsPlus and ASTER could make it easy, CSUN'94 "Technology and People with Disabilities", Los Angeles, March 16-19, 1994

2. Blenkhorn, Evans: A System for Reading and Producing Talking Tactile Maps and Diagrams, CSUN'94 "Technology and People with Disabilities", Los Angeles, March 16-19, 1994

3. Burger et al.: The design of interactive auditory learning tools, in: Burger, Sperandino (eds.), "Non-Visual Human-Computer Interactions", INSERM 1992, pp.97-114

4. Duennes: Putting Puff to Work for the Visually Impaired, SCREEN Printing, 58-62, Dec 1993

5. Hinton: Tactile and audio-tactile images as vehicles for learning, in: Burger, Sperandino (eds.), "Non-Visual Human-Computer Interactions", INSERM 1992, pp.169-179

6. Krämer: Automatische Übersetzung von Lehrgangsunterlagen in tastbare Dokumentationen für Blinde, Programmdokumentation, Innovative Techniken, Dresden 1993 
7. Lötzsch: Ebene Fachsprachen (Planar Specialized Languages), Thesis, Mathematische Kybernetik und Rechentechnik, Technische Universität Dresden, 1982

8. Lötzsch: Audio-taktiler Dialog über Graphiken und Diagrammen insbesondere für Blinde und Sehbehinderte, in: Mehnert (ed.), Proc. Konferenz "Elektronische Sprachsignalverarbeitung in der Rehabilitationstechnik", 22.24.11.1993, Berlin, Studientexte zur Sprachkommunikation, Heft 10, Humboldt-Universität Berlin

9. Lötzsch: Auditory Feedback from Tactile Pictures on Digitizing Tablets, Symposium on "High Resolution Tactile Graphics", Los Angeles, March 15, 1994

10. Parkes: Nomad, an audio-tactile tool for the acqusition, use and management of spatially distributed information by visually impaired people, in: Tatham (ed.), Proceedings of the "Second International Symposium on Maps and Graphics for Visually Handicapped People", A.F.\&Dodds, London 1988

11. Parkes: Nomad: enabling access to graphics and text based information for blind and visually impaired and other disability groups, in Proceedings of the world congress on Technology for People with Disabilities, Washington DC, December 1-5 1991, pp.689-716

12. TIDE 103: Textual and Graphical User Interfaces for Blind People, in "TIDE Pilot Action, The Synposes", CEC March 1992

13. VanderHeiden: Update on Access to Graphic User Interfaces by People who are Blind: Current Progress and Future Issues, CSUN'94 "Technology and People with Disabilities", Preconference session, Los Angeles, March 16-19, 1994 